\title{
La máquina en la vanguardia chilena ${ }^{1}$
}

\author{
Patricio LIZAMA A. \\ Pontificia Universidad Católica de Chile
}

\section{RESUMEN}

En este trabajo sobre autores de la vanguardia chilena, se analiza la manera como se articula la máquina en una modernidad periférica. En el mundo rural queda fuera de lugar por las condiciones coloniales; en la ciudad es rechazada porque desplaza a Dios como fundamento metafísico y a la vez es apropiada como índice de una modernidad futura. En el arte, es recibida como ícono de una nueva época y como instrumento que sirve al artista para revelar nuevos mundos, buscar la clarividencia y descubrirse a sí mismo.

Palabras clave: Vanguardia chilena, máquina, modernidad periférica.

\section{The Machine at the Forefront of Chilean}

\begin{abstract}
This article on authors from the Chilean avant-garde examines the representation of the machine on the periphery of the modern world. Excluded from a rural life due to the colonial conditions, it was rejected in the city because it replaced God as metaphysical foundation and was at the same time championed as an indication of future modernity. In art, the machine was received as an icon of the new epocah and as an instrument which enabled the artist to reveal new worlds, to search for prophetic powers and to discover his own self.
\end{abstract}

Keywords: Chilean avant-garde, machine, peripherical modernity.

SUMARIO: 1. La máquina extraviada en Alsino. 2. La máquina deseada en Marín. 3. La máquina visionaria en Miltín 1934. 4. La máquina idolatrada en Cruchaga. 5. La máquina apropiada en Agrella. 6. La máquina autorreflexiva en Neruda. 7. Palabras finales. 8. Bibliografía.

Para Angélica

A comienzos del siglo XX, la familia del escritor Juan Emar vive en Santiago a un par de cuadras del río Mapocho. El narrador de Umbral recuerda la vida de los niños en la casa y señala que desde el estrecho marco de la ventana colonial, "echábamos

${ }^{1}$ Este trabajo es parte del proyecto de investigación "La vanguardia chilena en sus revistas (1920-1930): modernidad, poesía e intelectuales”, Fondecyt No 1090735. 
un ojo hacia la calle" (Emar, 1996: 440). Desde allí ellos ven pasar el tranquilo devenir de los oficios, los animales y los artefactos del mundo premoderno basados en una tecnología preindustrial: el policía, el tortillero, perros vagos, ejércitos de ratas y una carretela tirada por un jamelgo. Al caer la noche, la casa se ilumina con el quinqué y la ciudad con la luz de los faroles a parafina y a gas que enciende el farolero. ${ }^{2}$

La limitada visión infantil se amplía y dinamiza con la mediación de la naturaleza y la aparición del tranvía eléctrico que reemplaza al "tranvía de sangre". ${ }^{3}$ La lluvia y los temblores provocan derrumbes y gran desconcierto, suerte de carnaval y espectáculo singular donde las normas y prohibiciones se suprimen, los fragmentos se desarman y rearman, las jerarquías se trastocan, las realidades subterráneas y olvidadas aparecen y todo es un gran desorden que solo se puede representar a través de una enumeración caótica: "surgían del desplome ratas y más ratas, cucarachas entumecidas, gatos de cien colores, trastos de otros siglos, zapatos abandonados, trozos de roperos y de trinches y un bastón" (Emar, 1996: 440-441). La agitación y el trastorno rompen la cadenciosa vida santiaguina y resultan imposibles de olvidar: "solo entonces, por todas partes a la vez, estallaba la primavera".

La irrupción del tranvía en septiembre de 1900, contribuye a expandir los límites de la capital chilena y dinamiza la vida de todos sus habitantes pues además de la gran novedad en el transporte, se inicia el servicio de iluminación eléctrica pública. Inolvidable resulta el relato de la inauguración de la primera línea de tranvías eléctricos en Chile: "Todo el pueblo se agolpaba en las ventanas y las aceras se hacían estrechas" para ver pasar a estos carruajes abiertos con una campana delantera donde iban las autoridades de levita, sombrero de copa y bastón, entre los que se contaba el padre de Emar. Los Yáñez Bianchi tenían motivos especiales para celebrar este acontecimiento pues si bien ellos conocían de lejos a los trenes que pasaban por los campos, nunca habían visto tranvías y menos pasar "por entre nuestras propias casas", cercanía que otorga un aire de maravilla y encanto: "Frente a mi casa, al alcance de mi mano, iba a pasar el primer cortejo: cinco o seis tranvías... ¡eléctricos!" (Emar,

${ }^{2}$ Carlos Sepúlveda en su novela Hijuna, a través de la figura del farolero, ofrece una alegoría de la difusión de las corrientes del pensamiento moderno en el mundo popular. La descripción está llena de poesía: “Anselmo, el farolero, silencioso y ágil, dibuja con el blanco de sus alpargatas, en la tierra negra, un fugaz revoloteo de palomas [...] ¡Qué envidia, qué tristeza nos da el no poder sembrar estrellas de una manera tan fácil: una escala y un fósforo [...]! (97) Hijuna. Santiago: Nascimento, 1971.

3 Llamados también "carros de sangre", el 31 de marzo de 1900, con carácter de ensayo, corrió el primer tranvía, viaje que se extendió solo por una cuadra. El 16 de mayo se hizo un ensayo de mayor envergadura pues el recorrido duró quince minutos y el tranvía cruzó por las calles Mapocho, Almirante Barroso y Avenida. Brasil. Finalmente, el 2 de septiembre del mismo año corrió oficialmente el primer tranvía para todo el público de Santiago. Véase el texto de Gonzalo Leiva et al., Luces de modernidad. Archivo fotográfico Chilectra. Santiago: Ril editores, 2001. 
1996: 441). El narrador agrega que estas máquinas ataviadas con flores y guirnaldas "Pasaban ¡Pasaban! Solas deslizábanse por los rieles” (Emar, 1996: 440-441). ${ }^{4}$

La máquina que atraviesa la ciudad también cruza por el centro de la literatura de vanguardia. Las tensiones entre tradición y modernidad, la modernidad vinculada a un orden cultural dominante que se instala como un acto impositivo y que a veces queda "fuera de lugar", los complejos vínculos existentes entre el centro y la periferia, entre una sociedad moderna y otra pre-moderna, entre Europa y América Latina, son algunas de las problemáticas que, a través de las variadas manifestaciones de la civilización científico-técnica, se pueden revelar en el vanguardismo. Asimismo, a través de la elaboración artística de la máquina podemos advertir cómo se transforma y aproxima el discurso ajeno, de qué manera la asociación de este con el discurso propio da origen a uno nuevo, y a la vez, a una cultura de la mezcla que se enraíza en el espacio latinoamericano. A partir de estos cruces y desvíos, de estas ajenidades y mediaciones, propongamos algunas lecturas de lo ocurrido con la máquina en el campo literario chileno de los años veinte y treinta.

\section{La máquina extraviada en Alsino}

La novela de Pedro Prado se desarrolla en el ámbito rural, espacio del que Alsino, el protagonista, desea liberarse y donde resulta imposible imaginar la modernidad: la máquina resulta una realidad lejana pues no es percibida y tampoco sabe usarse porque no existe una base material ni técnica que la hagan productiva. ${ }^{5}$

Alsino es un niño que vive en el campo junto a su hermano y a su abuela, en una "pasajera morada" que se encuentra rodeada por la arena, que se derrumba todos los años y que vive lejos de sus padres, los cuales están dominados por el alcohol y la miseria. Su anhelo es salir de este pueblo muerto que lo oprime, escapar al determinismo de la herencia, de la raza enferma y de la naturaleza que invade y destruye todo: él es un rebelde que desea abandonar la "residencia en la tierra" y logra su propósito a través de un largo proceso marcado por la recurrencia al mito y a procedimientos arcaicos.

El viaje comienza en el momento del sueño: "pasa por encima de la choza y la aldea [...] por sobre los montes de arena y cruza el lago a gran altura" (10). Sigue con el deseo: "anoche quería volar y volaba [...] No hacía nada, no movía los brazos, no saltaba; sólo quería volar y volaba" (12). Continúa con la revelación de su destino. Ve un buitre, asume que hay "algún animal muerto" y exclama: “¡Ya sé! ¡Ya sé!” (13). Aunque el narrador no explica lo sabido, comprendemos que el protagonista descubre que el cuerpo del animal es también, por analogía, el cuerpo de su aldea, del mundo rural, del país y que debe escapar y liberarse de este lugar donde se ha enseñoreado la muerte. La revelación culmina cuando Alsino y su hermano suben a un gran árbol,

\footnotetext{
${ }^{4}$ Los carros eran de color azul, con cupo para treinta y seis pasajeros sentados y su largo era de ocho metros. Contaban con una palanca y una campana de bronce y algunos tenían un segundo piso. A estos se les llamó "Imperial".

${ }_{5}^{5}$ Pedro Prado. Alsino. Santiago: Nascimento, 1974, $13^{\mathrm{a}}$ edc.
} 
con ojos fascinados y conmovidos observan el horizonte, intentan el vuelo y descienden huyendo enloquecidos y avanzando como ebrios, acontecimiento que confirma a Alsino como un vidente, alguien que tiene la "certeza de poseído" y la lucidez de un visionario (17).

El abandono del pueblo abre una nueva etapa que conduce al protagonista a explorar nuevos territorios, recorrer diferentes estratos sociales y experimentar un aprendizaje. Alsino vive una metamorfosis pues le crecen alas, asciende al cielo igual que Ícaro, contempla el conjunto de la creación, siente deseos de "decir y cantar" y formula un llamado a la naturaleza para que se libere: "huya de la espesura toda brizna libre". A la vez, con una aproximación mística de carácter figural, va al encuentro de la divinidad. Al referirse al sol, afirma: "subo a tu encuentro" y "mientras crece mi deseo de ti, extraviado vislumbro que se acerca la luz de tu eternidad" (82). Similar experiencia ocurre con el mar: "si reflejas al cielo, tú recuerdas a Dios" (89). Alsino se desmaterializa, su voz ya no es humana y en un movimiento ascensional de incansable tensión hacia la plenitud, vuela en un espacio infinito en busca de la otredad. Viaje metafísico, interior, que resulta un itinerario del alma.

El visionario luego desciende, se materializa, recorre el campo y advierte la degradación, la estructura productiva tradicional y las huellas coloniales que lo presiden. La primera parte de este viaje culmina en una hacienda en ruinas, en la cual el antiguo poder económico del terrateniente, su continuo poder político -"audacia en el manejo electoral"-, el control de la policía, la autoridad sobre su familia, el abuso de los campesinos y sus mujeres, configuran un espacio cerrado de rasgos infernales, imagen viva del campo y de la "cuestión social" en el país. ${ }^{6}$ Alsino allí es tomado preso y su cuerpo es mutilado, ofrecido como mercancía, objeto para exhibir y considerado un poseído por un maleficio. Fuera de este territorio, segunda parte de la peregrinación, su vida no es mejor pues es rechazado y agredido por los habitantes de los poblados, queda ciego producto de una venganza, no entiende los códigos del amor y su diferencia termina por confundir. Viaje terrenal, exterior, que ofrece una visión crítica del alma del país.

La máquina, en este contexto, no tiene ninguna cabida. El hacendado implanta "novedades extrañas" como una "enorme rueda hidráulica", pero no hay conocimientos ni infraestructura para acoger la modernidad: las piezas se rompen, los herreros competentes no llegan, nunca concluye la construcción de "la tonelería y taller que la rueda debía servir" (135) y esta termina "pudriéndose" de modo que el dueño "un buen día, colérico" mandó "rueda y todo, al diablo" (135). El aeroplano no tiene mejor suerte porque al acercarse al caserío quienes lo ven sienten "un enorme desprecio ante la inaudita ceguera de los que nunca lograban divisarlo" (187), e incluso, todo se distorsiona porque los borrachos interpelan a Alsino, "aquí está el volador", le piden que vuele y terminan por agredirlo. El aeroplano emprende su

\footnotetext{
${ }^{6}$ Inevitable resulta la relación con la novela de José Donoso, El lugar sin límites.
} 
ascenso y al mismo tiempo, el protagonista escapa por los aires. Ni el aeroplano ni Alsino son legibles: uno por moderno, otro por arcaico.

Alsino, igual que sus viajes, está tensionado dentro una estructura dual. Tiene alas "que lo remontan a la esfera superior, sin dejar, por eso, de seguir perteneciendo a la tierra" (Subercaseaux: 62). Se eleva para liberarse del espacio que lo oprime, pero el determinismo y las fuerzas retardatarias se lo impiden. Asciende para buscar una presencia divina, accede a algunos vislumbres de la otredad, pero termina desintegrándose. La novela posee una dialéctica similar. El narrador construye un relato descriptivo que se constituye en un documento de la realidad inscrito en el naturalismo y dentro de este relato, aparecen destellos de una visión vanguardista, de una búsqueda de otras regiones de la naturaleza que se expresa en el discurso de Alsino a través de alegorías, revelaciones, delirios y profecías.

La modernidad (la máquina) y el artista (el vidente) representan el discurso de lo nuevo que trata de insertarse, pero este se enfrenta a un espacio donde predominan enclaves y estructuras de rasgos coloniales, un discurso oligárquico operante y una sociedad tradicional de espaldas a lo nuevo. La desintegración de Alsino y la inutilidad de la máquina nos hablan del extravío de la modernidad y del artista de vanguardia en el Chile de comienzos del siglo XX: ambos están "fuera de lugar". Pero además, los signos de muerte aluden a toda una civilización que camina hacia un tiempo apocalíptico pues está enclaustrada por la hegemonía de la racionalidad. Por ello, hay que romper "la vieja tela de la razón" y abrirse a otras dimensiones de lo real que le permitan al hombre ampliar su conciencia.

La novela propone esta apertura aún precaria, al incorporar espacios de irracionalidad en el naturalismo y también en la conformación de Alsino. La contradicción entre lo rural y lo moderno, entre el hombre y la máquina, entre el infierno y la utopía, se resuelve con la mediación de un objeto intermedio, Alsino, que es un hombre-máquina, un sujeto contrahecho, es "el volador", la figura confundida y atacada, la imagen de la modernidad periférica a comienzos del siglo XX. Alsino desenmascara una sociedad que requiere una profunda transformación como base necesaria para el desarrollo de lo nuevo.

\section{La máquina deseada en Marín}

En la poesía de Juan Marín se advierte el impacto de los descubrimientos e invenciones de la tecnología y el entusiasmo en el poder de la máquina y su capacidad para conducir a espacios inexplorados y revelar vistas insospechadas. En este sentido, la impronta del futurismo resulta relevante para este escritor que con su poesía, busca capturar el dinamismo universal, plasmarlo como sensación dinámica con nuevas imágenes y a la vez, reflexionar acerca de los desafíos antropológicos y religiosos que supone la época emergente.

Los poemas se articulan como viajes a nuevas zonas de realidad. A veces, todo comienza en un auto, el conductor y su musa Monna avanzan por la carretera y a 
causa de la velocidad, el trayecto se transforma en vuelo al espacio. ${ }^{7}$ Otras, el viaje se realiza en un "superavión" guiado por un "corazón piloto", hombre que si no es suplantado por el objeto técnico, sí está en estrecha dependencia con la máquina que se ha convertido casi en su segunda naturaleza, y que resulta ya muy alejado de Alsino. También el viaje es juego pues en coincidencia con el personaje de Pedro Prado, el piloto es un "niño con alas" que guía al avión con movimientos audaces a base de espirales interminables y grandes oscilaciones que construyen la "futura chancón / lirismo de la síntesis mecánica". ${ }^{8}$

La manera de nombrar al avión revela la ambigüedad de la tecnología ya que este es una belleza armónica, sublime, una "mariposa férrea" donde confluyen la naturaleza y la industria, el prodigio y la liviandad del vuelo con la solidez del material base de la nueva arquitectura. Pero asimismo es "moscardón de la muerte", un aparato para destruir y quitar la vida que asocia la naturaleza con la industria al servicio de la guerra. Además, es "tirabuzón de hierro", artefacto para explorar, conocer lo nunca visto y establecer nuevas relaciones entre los cuerpos que habitan el espacio: avión como instrumento de conquista y conocimiento. Por último, el avión es un "lindo juguete" en manos de un niño, propuesta que expresa la contradicción y la desmesura del anhelo latinoamericano por alcanzar una modernidad, pues si bien el piloto maneja con destreza la aeronave, también el piloto es un niño que solo juega con el Curtiss Hawk (la máquina): la domina y también la simplifica y reduce a un juguete. ${ }^{9}$ La profusión de diversas máquinas en estos poemas revela el afán de modernidad, "futura chancon", que si no se advierte en términos reales, se logra a nivel de lo simbólico. Lo revelador es que el logro resulta degradado en su base porque la adaptación/ traducción está mal hecha: es una errata. ${ }^{10}$

El viaje que en Marín siempre supone dirigirse a los confines del universo, tiene dos momentos. El abandono de la tierra conlleva un quiebre radical con los fundamentos de la civilización occidental y de todo "ese mundo antiguo" como diría Apollinaire. En el poema "Klaxon" se rompe con la naturaleza, el arte y la cultura del pasado pues producto de la velocidad, los objetos se desfiguran, y resultan "comprimidos", "cinematograficadózimamente". Advertimos que la pareja no solo se libera del "velo de atavismo y cultura", sino que además, accede a un nuevo mirar que

${ }_{8}^{7}$ El poema "Klaxon" se puede leer como una cita en verso del primer manifiesto futurista.

8 La errata "chancon" en vez de "chanson" aparece en el poema "Spin" del libro Looping de Juan Marín Santiago: Nascimento, 1929.

9 Hawk era el nombre común para denominar a los aviones, la mayoría de ellos de combate, diseñados y producidos por la Curtiss Aeroplane and Motor Company.

${ }^{10}$ El afán civilizador de Sarmiento posee en su base una degradación muy semejante. El Facundo comienza con una cita del francés que está mal hecha, equivocada, falsa. Piglia señala: "En el momento en que quiere exhibir y alardear con su manejo fluido de la cultura europea, todo se le viene abajo" (128). Así también, cuando el piloto de Marín quiere alardear de su manejo fluido del avión y simbólicamente aludir a la modernidad deseada, aparece una errata y todo se le viene abajo (Véase Ricardo Piglia. Respiración artificial. Buenos Aires: Sudamericana, 1992, $4^{\mathrm{a}}$ edc.). 
la habilita para comprender una belleza moderna y dinámica. Se cancela la percepción propia de "ese mundo antiguo" unida a la contemplación, el recogimiento, el abandono ante lo expuesto, y se propone una nueva que está mediada por la técnica, se vincula al shock producido por el cambio veloz de las imágenes, y posee un carácter fragmentario ligado a la dispersión. ${ }^{11}$

Al traspasar los límites de la tierra y dirigirse a las "sombras del cosmos", el viaje cobra un nuevo carácter. El avión "perfora", "excava", sale de "caza" hacia mundos ignotos de dimensiones abisales. El espacio cambia, es un campo de fuerzas muy distinto a la superficie más o menos estable de las antiguas cosmologías y filosofías, el tiempo se experimenta como un torbellino y se rompen los ritmos cósmicos de las viejas civilizaciones ${ }^{12}$, de modo que el hombre modifica la percepción y regula de otra manera la sensibilidad y la actividad de los sentidos. Además, se desprende de dimensiones esenciales de su naturaleza como el recuerdo y la memoria, el encuentro y el amor, vaciamiento que otorga una identidad antropológica renovada presidida por una voluntad de poder. Este "pequeño dios" anhela superar los límites de su naturaleza y generar una nueva creación, afán de dominio que crece con las visiones nunca vistas, el establecimiento de nuevas relaciones, leyes y fuerzas entre los cuerpos que habitan el universo. De esta forma, con el superavión, "el hombre afirma su existencia milenaria".

La conquista del aire, antiguo sueño del hombre, significa "el fin de la dependencia terrestre y del reinado oceánico" (Giucci: 112). El vuelo de Marín implica así la culminación de la tradición del impulso ascendente que representan Ícaro en la mitología griega, más tarde Dante en los poetas del dolce stil novo y San Juan de la Cruz entre los poetas místicos; del viaje ascendente de los románticos como Novalis; en la tradición chilena, de los intentos de Alsino y Altazor. El viaje en Marín aparece como una superación del imaginario vinculado al vuelo dentro de estas tradiciones, para transformarse en uno moderno, exterior, de poder y control del universo: hay ascenso, pero no hay caída. ${ }^{13}$

El hombre que viaja de la tierra al cosmos ya no admira el poder de Dios, anula las dualidades propias del pensamiento religioso tradicional -más allá/más acá- y borra la oposición entre trascendencia/inmanencia pues como sostiene Sergio Silva, la primera "pasa a ser concebida como la inmanencia de ese futuro que creará el trabajo del hombre" (Silva, 1985: 21). El racionalismo, la confianza en la razón humana, termina por renegar de Dios y desplazar a la fe religiosa de modo que el desarrollo

${ }^{11}$ Véase Walter Benjamin, "La obra de arte en la época de su reproductibilidad técnica", en Discursos interrumpidos. Vol. 1. Trad. Jesús Aguirre. Madrid: Taurus, 1973, pp. 17-57.

12 Véase Octavio Paz. El arco y la lira. México: F.C.E, 1981.

${ }^{13}$ En el relato de Pedro Prado titulado La Barca de Los Diez esta abandona el mar y alcanza el espacio y en este sentido, se asemeja al auto de Marín, pero el viaje de Prado no es moderno ni futurista porque más que de dominio y conquista, es de búsqueda y trascendencia. Aunque se deshacen los límites del tiempo y el espacio, no existe voluntad de romper con el orden de la creación. Véase Los Diez. Santiago: Universitaria, 1915. 
científico y técnico parece culminar en una sociedad desacralizada y en la muerte de Dios, característica de la modernidad según Silva (Silva, 1981: 83).

La poesía de Marín se articula sobre nuevas creencias. El movimiento deja atrás a la quietud; la ciencia y la tecnología, a la naturaleza y a la cultura antigua. El poder del hombre, el maquinismo y su capacidad de transformación, las posibilidades de construir(se) ofrecidas por la razón, configuran un ethos cultural moderno, de señorío autónomo y de dominación mediante la técnica de base científica que niega la otredad. Moderno también es el modo de percepción sensorial porque de la lentitud pasamos al torbellino; de la contemplación de la pintura al dinamismo del cine y de esta forma el viaje comienza entre los dispersos escombros de la civilización antigua y culmina en la utopía de una nueva.

La paradoja es que estas convicciones no logran fabricar un poema con una estética moderna. La agitación y el vértigo, Marín los revela con un léxico futurista, pero no los plasma con procedimientos nuevos, no los expresa visualmente en el poema. El hace una lectura dependiente del texto ajeno, pero sin "palabras en libertad". De esta forma, ocurre lo señalado por Huidobro: "Si canto al avión con la estética de Víctor Hugo, seré tan viejo como él". Solo en el poema "Spin" notamos un dinamismo en la tipografía y la composición que acompañan al mensaje lingüístico.

\section{La máquina visionaria en Miltín 1934}

En esta novela de Juan Emar, el protagonista es invitado por el capitán Angol a realizar cuatro "vuelos fantásticos" los cuales están presididos por un desajuste del yo consigo mismo y con el mundo, lo cual genera el deseo de ampliar los límites del hombre y hallar nuevas posibilidades de existencia. La complejidad de la mirada en los dos primeros viajes se construye a partir del poderío de la máquina y la habilidad del piloto que permiten alcanzar el espacio cósmico y observar el mundo desde distintos ángulos. De este modo, se abandona la perspectiva única y la imagen fenoménica de las cosas y, en su reemplazo, se propone una visión cubista que busca expresar la esencia de la realidad a través de perspectivas complementarias y simultáneas y así configurar la representación de una imagen total y la revelación de un conocimiento absoluto. Desde gran altura se mira hacia abajo -Santiago se aplana, los cerros se desinflan; hacia la derecha la cordillera se agiganta y luego el narrador se ubica sobre esta y logra verle la cara, "su razón de ser", proceso que reitera al dirigirse al sol. Así, el narrador aprehende varios lados y distintos momentos del objeto.

El acceso a estas realidades desencadena variadas conjeturas, ejercicio autorreflexivo muy propio de la obra emariana. El narrador trata de ver los elementos en sí mismos, despojados de las creencias asignadas por el hombre, puesta entre paréntesis que le permite redescubrirlos en su naturaleza más esencial pues si bien son parte de la cotidianeidad, por el hecho de contar siempre con ellos, dejan de apreciarse en su carácter dinámico y en su naturaleza viva. Al mismo tiempo, advierte que esta alteridad relativiza el poder del sujeto pues en cuanto se aprehenden con un enfoque relacional otras realidades, surge el miedo al ver "agrandarse todo y achicarse uno". En este sentido, el protagonista asume que el hombre posee un 
conocimiento precario porque su naturaleza lo limita y le impide captar la totalidad y por ello confiesa "haberme sentido a mí mismo con todos los hombres [...] viviendo como piojos inconscientes" (Emar, 1935: 159). La revelación establece la certeza de un plano de "existencia sórdida, nebulosa, agazapada sobre la tierra" y otro de "existencia solitaria, vibrante en el espacio", convicción que está en la base del vuelo. Pero además, indica la conciencia de que el hombre ha olvidado "la cara de allá arriba", la dimensión cósmica y trascendente, olvido que explica la necesidad de "elevación" del narrador.

El trabajo perceptivo e intelectivo se pliega sobre sí mismo y se desdobla porque, suscitada por las piruetas del avión, surge la reminiscencia de un proceso semejante. ${ }^{14}$ Este ocurre en otra dimensión de existencia y en otro tiempo, en un pasado remoto cuando el narrador era "un mosquito" y volaba para descubrir una presencia inquietante que adopta la forma de una inmensidad velluda que posee uno y más tarde varios ojos. A su vez, el vuelo del insecto, nuevo pliegue y analogía del relato, confiesa el narrador que se asemeja al del avión. ${ }^{15}$ El mosquito se acerca al misterio, comunica este descubrimiento a sus semejantes y sólo algunos se interesan por desentrañar el enigma. El narrador señala “¡cuánto buscamos!”, y si bien recuerda que al comienzo tuvieron pánico de la multiplicidad, el desconcierto hizo nacer el inquebrantable deseo de "dejar de ser mosquitos", transmutación en sentido ascendente que logra en el tiempo por medio de sucesivos nacimientos y alcanza la dimensión humana. Así logra ver y también ser visto porque el sol es un ojo "que veía obedeciendo a mayores vidas" (Emar, 1935: 169).

Los viajes del narrador se convierten en alegoría del artista de vanguardia, de su enfrentamiento con nuevas regiones de la naturaleza y de su anhelo de clarividencia para poder comprenderlas y representarlas. Su desajuste inicial da paso a un extrañamiento frente a su propio sistema de creencias y a una intelección renovada de la realidad, la cual se facilita por la distancia espacial que interpone entre él y el mundo terrenal. La metamorfosis que supone crisis y renacimiento, enfatiza el proceso del artista que logra ver y se convierte en otro, pues abandona un estado y accede a uno más pleno que trastorna su percepción y amplía su conocimiento

La máquina y sus movimientos, el pliegue y despliegue de su vuelo, son equivalentes a las vueltas del relato, a los desdoblamientos y a la articulación relacional que este supone. El primer vuelo está en relación con el segundo; el descubrimiento del narrador en el avión se lee vinculado al del mosquito en el pasado. El acercamiento al sol y la iluminación que ello supone, se pone en relación con el acercamiento del mosquito al ojo. En ambos casos, el logro es la clarividencia.

${ }^{14}$ El narrador afirma: "en una de esas piruetas, me hallé por un instante, con el cerebro descargado, frente al Sol. Entonces el recuerdo salió a flote" (Emar, 1935: 161).

15 En cuanto mosquito, señala el narrador, di "dos vueltas, tal como hacen ahora los aviones y muy especialmente este de nuestro capitán Angol” (Emar, 1935: 162). 


\section{La máquina idolatrada en Cruchaga}

Las interrogantes metafísicas y la denuncia de la modernolatría ante la máquina son problemáticas que encontramos en el poema "Avión” de Juan Guzmán Cruchaga publicado en las Notas de Arte de Juan Emar. El avión es aventurero moderno que deja atrás a las figuras de la civilización grecolatina -“Ícaro solloza"- que encarnaban el imaginario del vuelo en su afán de trascender los límites de la condición humana y acercarse a las realidades superiores. Es "explorador" que se interna por paisajes desconocidos, se sumerge en las fronteras del universo, examina y divide las referencias básicas para una orientación normal en el mundo - "los puntos cardinales", "el día" y "el sol"- y así, al ampliar el espacio hasta lo infinito y desarticular su legalidad, se pierde la imagen del mundo. Es un "volatinero" que resplandece en el cielo y con la belleza y el arte de sus giros y movimientos, con la habilidad y el poder de su vuelo, se convierte en un nuevo ídolo que cautiva al hombre: "la ciudad te contempla".

El avión desplaza los pilares del mundo antiguo y al fundamento suprasensible, de modo que la autoridad divina se reemplaza por la de la conciencia y la razón y el esfuerzo creador, otrora propio del Dios bíblico, se convierte en quehacer distintivo del hombre. No se trata de poner a este en el lugar divino, pero como el espacio queda vacío, el hombre, a su medida, lo ocupa con otros dioses entre los cuales la modernidad posee un puesto central. Ante ello, el hablante puntualiza diversos problemas.

La valoración del poder científico-técnico como medio para el crecimiento personal y el progreso humano coexiste con la sospecha respecto a que aquel no cumple sus promesas de plenitud y no brinda un desarrollo armónico. Al contrario, genera enormes desequilibrios en la sociedad, "torres de oro" conviven junto a barrios humosos", atenta contra la naturaleza, "el sol se vuelve gris", y aleja a Dios de su horizonte. La desconfianza del hablante, además, se centra en la operatividad de los mecanismos que implementa la sociedad para controlar los costos y los mal llamados efectos secundarios que tiene el desarrollo en la vida humana.

El conocimiento y el dominio sobre la naturaleza junto a la capacidad humana para diseñar la moderna cultura del progreso, en la medida que se independizan y se desarrollan sin un control ético- moral, configuran para Cruchaga una idolatría y por ello, la desarticula de dos maneras. Él denuncia a los habitantes de la ciudad que contemplan a la máquina y se maravillan ante sus prodigios, pero que no advierten los trastornos que causa el avance científico-técnico. Luego, como no concibe una humanidad sin la experiencia de lo sobrenatural y no se resigna a la expulsión de Dios de la historia humana, interpela al avión: “¿Explorador azul, viste en el cielo / a Elías en su carro fulgurante / pescando estrellas?".

La alusión intertextual del profeta Elías quien "despertó a un cadáver de la muerte", evidencia el deseo de Cruchaga por reinstalar el fundamento religioso en la escena de la modernidad pues desde su perspectiva, todo lo creado tiene un origen y un fin divinos; de lo contrario, como dice en otro de sus poemas publicados en $L a$ Nación: “qqué prestigio tendrán las cosas si tú no las atraviesas con tu brillo?” (Emar, 2003: 122). Si todo profeta polemiza y ejerce una resistencia frente a los falsos ídolos 
que se enseñorean del cielo, podríamos asumir que la disputa que atraviesa el poema es la que se verifica entre el avión y el profeta. Si el avión es "sembrador de estrellas", Elías hace lo opuesto, está "pescando estrellas"; si el avión y su luz dominan el cielo, el carro y su fulgor suben a disputar el dominio del cielo; si el poder del hombre logra desarticular la creación, la esperanza es que se pueda restituir el orden; si la ciudad contempla al avión, la esperanza es que esta pueda contemplar a Dios. El enfrentamiento se resuelve a favor de Dios porque después de la pregunta por Elías, el avión cae sobre el llano, se convierte en "sombra inmóvil" y el cielo recupera su fisonomía.

La propuesta de Cruchaga no es condenatoria de todo lo que encarna la máquina ya que la concibe vinculada a la autonomía y a la libertad del hombre. Lo que él advierte es la necesidad de establecer límites a esa misma libertad con el propósito de resguardar a los más débiles y a los marginados del desarrollo, que son quienes sufren las consecuencias negativas del progreso.

\section{La máquina apropiada en Agrella}

Neftalí Agrella escribe el poema "La gran Rueda" en 1922 y en 1924 lo publica en la revista Nguillatun. Un año más tarde le introduce pequeñas variantes y lo recoge en el libro Poemas. En la revista, junto al poema, aparece una breve crónica escrita por el propio autor, la cual resulta muy interesante porque nos revela algunas dimensiones de la modernidad y también la manera como estas se reciben desde el margen. Revisemos la crónica.

La gran rueda que llega a Chile es parte de una muestra integrada por carruseles, tómbolas, carros locos, el motociclista de la muerte y una extraña niña llamada Olga. El parque de atracciones proveniente de Nueva York que se anuncia como Coney Island Show, se instala en Valparaíso en 1922. Un año más tarde regresa a este puerto y en 1924 el parque de atracciones lo encontramos en Curicó, pero se denomina Luna Park. El cambio de nombre es un índice de cómo se apropia lo recibido de afuera porque primero mantiene su denominación en inglés, pero más tarde se modifica y el nuevo nombre se construye sobre la tensión irresuelta que une y enfrenta al español y al inglés, tensión que indica el desarrollo de una cultura de la mezcla que es nueva, original y que resulta del roce entre lo ajeno y lo propio.

A esta transformación se superpone otra, la ocurrida con la gran rueda, la cual devela un nuevo aspecto del apropiar. En Santiago, es colocada en "la avenida de las Delicias" y se asemeja a un "exorbitante árbol que sobrepasara la ciudad". La máquina entonces se enraíza ("árbol"), se adhiere ("enredadera"), da luz ("luminosa") y se humaniza ("costillas desnudas"). Ya arraigada, el poeta le otorga un fundamento nuevo pues la concibe como un "edificio imaginado por un arquitecto absurdo", lleno de dinamismo y energía que "da vueltas como un planeta" y tiene una "vida ondulante". Agrella le confiere una tercera existencia en cuanto la gran rueda se configura como espacio practicado, ya que no solo es objeto a contemplar sino artefacto habitable: acuden a ella "familias endomingadas y novios de feria". Por 
último, agreguemos que la gran rueda y el parque de atracciones se terminan de enraizar y apropiar en cuanto se convierten en escenario de novela. ${ }^{16}$

La crónica, a su vez, nos muestra la implementación de algunas dimensiones modernas y los modos de experimentarla, todo ello en el contexto de la experiencia de la metrópoli, escenario donde se representan los espectáculos de la modernidad y se vive la conmoción de lo nuevo. La presencia del parque de atracciones en Chile nos habla de países donde, al menos por un período, surge un verdadero enclave de lo nuevo, núcleo y fundamento de valor de la vanguardia. La gran rueda, "señal de los aviadores" y "enredadera luminosa", indica el interés por la máquina que lleva en círculo a las alturas, ofrece nuevas vistas de la realidad y ángulos diferentes porque "las gentes ascienden retrocediendo" y "los ojos creen cruzar, por fin, el umbral del cielo" (Del Valle: 29 - 30). Indica además, la fascinación con algo menos apreciado, pero que "equivale a una revolución cultural", la energía eléctrica que reviste la vida cotidiana de cualidades inimaginables, crea un entorno de mundo de hadas y la sensación de encontrarse, no en un lugar lejano, sino en un lugar de ensueño" donde los milagros de la velocidad y el movimiento ofrecen un paisaje de luces que se extiende por la ciudad (Williams: 239). Otra dimensión moderna radica en el parque de atracciones que se constituye como expresión de una cultura moderna de masas y de una industria del entretenimiento que congrega a la multitud, espacio colectivo que tiene un contenido de exigencias igualitarias que son la energía presente en la masa y dentro de la cual se encuentra el artista. Él transita en medio de la escena urbana de la que, a la vez forma parte, de modo que es un paseante, un observador anónimo, y asimismo, un participante que usa la máquina.

El impacto que tiene la tecnología en el trabajo del artista agrega una nueva realidad moderna. El creador desarrolla un sensorium con modalidades perceptivas desconocidas. No se trata solo de la aparición de un "nuevo ojo" que se abre a renovados criterios de belleza derivados de la simpleza de las formas, la funcionalidad armoniosa y los principios constructivos emergentes. Se trata de una percepción sensorial basada en el acercamiento y en un nuevo acceso a las cosas que "pone a cualquier hombre en posición de usarlas y gozarlas" (Barbero: 58). Agrella explicita lo anterior al confesar que con Alberto Rojas Jiménez se subieron a los carruseles, a la gran rueda y a los carros locos y que estos en particular, "producían sensaciones despampanantes". Y añade: en los juegos "percibimos nuevas sensaciones de su dinamismo y belleza". Advertimos que la rápida y continua alternancia de impresiones externas e internas, la apretada sucesión de imágenes cambiantes, la brusca diversificación en el interior del plano que se capta, el carácter inesperado de las impresiones que se imponen a la atención, todo ello nos muestra la intensificación de la vida psíquica y un sistema sensorial moderno vinculado a la

${ }^{16}$ Un fragmento de la novela Eva y la fuga de Rosamel del Valle, transcurre en el parque de atracciones Luna Park. 
dispersión. ${ }^{17}$ En otro texto señala que los carros locos implican una "inversión de todos los planos de la atmósfera" y concluye: "se juega al football con los ojos"

La gran rueda, en el poema, se define como "ferrocarril interplanetario" que conecta al hombre con el cosmos y que hace el recorrido entre la tierra, "estación terminal" y Júpiter, "estación inicial". Nosotros podríamos decir que también es un "ferrocarril interoceánico" que vincula al centro con la periferia, a Nueva York con Curicó, a la modernidad con la tradición, en un viaje de ida y vuelta similar al final de Rayuela, porque para el poeta de la modernidad periférica existe una apertura que no se cierra pues no hay estaciones terminales ni iniciales y existe un salto que siempre nos moviliza hacia el lado de allá y el de acá y nos deja entre.

\section{La máquina autorreflexiva en Neruda}

La presencia de la máquina en Crepusculario, aunque poco numerosa, posee diversas significaciones complementarias que resultan centrales para el conjunto del libro. Podríamos entender una dimensión del poemario con la ayuda de la cámara fotográfica. En el poema "Mancha en tierras de color", el hablante se inclina sobre un pozo y del fondo de este "me veo brotar / como en una instantánea de sesenta cobres / distante y movida. Fotógrafo pobre". El gesto autorreflexivo y los elementos que lo constituyen tienen rasgos de actitud narcisista pues el yo poético en su autocontemplación, hace referencia a la imagen de sí mismo que brota del agua, fuente de todas las potencialidades de la existencia y forma primera de la materia. Esta relación especular implica que el yo pone énfasis y se orienta no tanto sobre los objetos que conforman el mundo que lo rodea, sino que más bien se dirige al reconocimiento de su propio yo. Así, el sujeto del poemario aunque se abre a la integración de la alteridad que le causa dolor o placer, aunque se dirige y se deja seducir por el modelo del otro, retorna luego a la contemplación de su imagen, se toma a sí mismo como centro de interés y termina descubriéndose y revelándose: el objeto existe para las necesidades del yo pues ante las aguas, este coloca su mundo interior como eje del mundo.

El gesto autorreflexivo se puede vincular de otra manera al yo del poema. La representación alterada del sujeto debido al movimiento del agua que cual espejo lo refleja y le devuelve su rostro, se compara con el retrato distorsionado resultante de una toma precaria que realiza un "fotógrafo pobre". Este artista resulta ser el propio sujeto de Crepusculario que captura fragmentos de realidad y retrata el entorno a través de un ojo/máquina, mediación ligada al conocimiento del conjunto de percepciones exteriores y a la facultad de visión intuitiva. La preocupación por capturar la imagen que brota de la "instantánea" indica que el interés se halla puesto en el conocimiento de sí mismo y no tanto en el paisaje exterior que se aprehende, de manera que el motivo elegido que preside el encuadre de la fotografía, el objeto

17 Véase Georg Simmel, "Las metrópolis y la vida espiritual", en Tomás Maldonado (comp.). Técnica y cultura. El debate alemán entre Bismarck y Weimar. Buenos Aires: Ediciones Infinito, 2002, pp. 55-68. 
central de la escena, es el yo captado con un enfoque y una profundidad de campo limitada que lo resalta en forma nítida frente a todo lo demás. Agreguemos que la condición de pobreza y marginalidad del artista configura una nueva distancia, reveladora de la precariedad vital de quien enuncia el discurso poético y del amplio espacio que se interpone entre él y el mundo, lo cual condiciona la toma que resulta confusa y ambigua, "distante y movida". La máquina retrata así la situación del artista a comienzos de la década del veinte, poeta que se halla en un margen del campo intelectual chileno y que comienza a encontrar una voz para su decir.

El gesto analizado y en particular el proceso de verse "brotar" en/desde el agua, puede leerse desde una nueva dimensión: el nacimiento. Crepusculario es el primer libro de Neruda con el que el joven escritor ingresa al campo cultural chileno y nace como poeta. El gesto autorreflexivo del sujeto es también nacimiento porque la imagen del yo surge del fondo del pozo, ${ }^{18}$ agujero en la tierra de carácter sagrado, revelador de la abundancia y de la fuente de la vida, principio y fin de todas las cosas de la tierra, que contiene aguas profundas y subterráneas desde donde surge todo lo viviente, motivo por el cual el pozo está ligado al principio femenino, al útero de la gran madre ${ }^{19}$ : el yo poético se desdobla y accede a la contemplación de su propio parto.

Si el verse "brotar" en el agua se compara al verse "brotar" en una "instantánea", revisemos el nacimiento desde la fotografía. Esta "es literalmente una emanación del referente" (Barthes: 126), una imagen salida, revelada, por la acción de la luz, y es siempre "una contingencia" pues en toda foto existe algo representado. En este caso, la foto captura un momento crucial del joven Neruda, el nacimiento de su identidad como artista, y (le) muestra lo que estaba escondido y comienza a aflorar pues lo que asciende desde las aguas/ la foto, es el hombre que ha alcanzado una verdad, un conocimiento de carácter numinoso relacionado con la inspiración del artista.

Una nueva nota del nacimiento ligado a la fotografía surge al considerar que esta es "el advenimiento de yo mismo como otro: disociación [...] de la conciencia de identidad" (Barthes: 40). En el verse "brotar" de Crepusculario, el hablante se desdobla de dos maneras. El yo, el que vive, (Neftalí Reyes) se mira a sí mismo como otro, el que escribe, (Pablo Neruda), nombre con el que firma su primer libro. Al tachar el nombre propio que estabiliza al yo y darse uno nuevo, nace a una identidad que lo complementa. Al mismo tiempo, existe otro desdoblamiento en cuanto el sujeto se transforma en objeto, y él mismo logra autentificar la evidencia del momento en que nace su libro y su identidad poética: el operador de la foto resulta ser el mismo sujeto que el espectador.

18 Freud señala que en los sueños, el nacimiento "es casi siempre representado por una acción en la que el agua es el factor principal" (Introducción al psicoanálisis. Madrid: Alianza Editorial, 1995, pp. 158, $21^{\text {a }}$ edc.).

19 Véase los diccionarios de símbolos de Juan Eduardo Cirlot, Jean Chevalier y Jean Cooper. 
Las circunstancias del nacimiento que el propio artista y nosotros observamos en Crepusculario, no quedan registradas solo en este libro ya que Neruda en Confieso que he vivido y en Memorial de Isla Negra, reescribe en prosa y en poesía este episodio. El nacer, ahora mediado por la distancia temporal y enriquecido por la voluntad autobiográfica, es otra vez "fotografiado", lo que implica un nuevo gesto autorreflexivo pues el escritor contempla y reelabora el gesto autorreflexivo primero. Lo atrayente de este volver al pasado es que con estas dos nuevas fotos nerudianas ocurre algo semejante a lo sucedido con las fotografías que articulan las historias de Blow Up de Antonioni y de Apocalipsis en Solentiname de Cortázar: el encuadre de la escena original se amplía, la profundidad del campo es mayor, la capacidad de visión se agranda y así se abarcan realidades antes excluidas, se advierten detalles con nitidez y se complejiza el registro del suceso. El retrato del yo de Crepusculario deviene paisaje en Confieso... y Memorial; el gesto autorreflexivo es el mismo y es otro; la autorrepresentación es la misma y es otra. Revisemos cómo Neruda adulto expande el suceso y hace estallar al yo narciso.

En Confieso... el poeta evoca su viaje veraniego a la casa del agricultor Horacio Pacheco, la cual está situada en la desembocadura del río Imperial; el poeta lo recuerda con claridad pues fue en aquel viaje donde por primera vez vio el mar: "Desde los muelles desvencijados donde atracó el vaporcito, escuché a la distancia el trueno marino, una conmoción lejana. El oleaje entraba en mi existencia" (Neruda, 2005: 22). En esta casa de Puerto Saavedra, a orillas del Océano Pacífico, Neruda nos cuenta que había un gran jardín salvaje y extraño donde solo había amapolas y un no menos extraño y fascinante "bote grande, huérfano de un gran naufragio, que allí en el jardín yacía sin olas ni tormentas, encallado entre las amapolas" (Neruda, 2005: 22). Agreguemos nosotros que allí también, en medio de estas amapolas, se encontraba el pozo de Crepusculario.

El poeta intenta así "corregir" el pasado y construye otra imagen personal pues en sus memorias, omite el pozo y en su reemplazo coloca el bote enterrado, cambia una sinécdoque del mar por otra. Objeto desplazado de su lugar natural, la embarcación es un elemento extraño en el jardín y esta convergencia inusual y en apariencia inconciliable, configura una verdadera imagen surrealista y además nos recuerda episodios narrados por los cronistas de indias. Lo otro que resulta desplazado de su lugar es el yo de Crepusculario pues el escritor oculta y olvida al sujeto adolescente replegado en sí mismo que se ve brotar en el pozo, y en cambio, pone todo el énfasis en el yo que descubre el mar. Podríamos señalar que así como la furia desatada del océano arroja al bote a la costa y lo entierra en el jardín, Neruda en Confieso... entierra al yo narciso y contemplativo del pozo y lo reemplaza por otro que está abierto al dinamismo y a los avatares del mundo.

La evocación del viaje a Puerto Saavedra en Memorial de Isla Negra la encontramos en el poema "El primer mar" y como lo indica el título, su centro de interés está puesto en el descubrimiento del mar y el cambio que ello supone en el escritor. El hablante se recuerda como un sujeto perdido, extraviado en el mundo adulto del pequeño vapor que traslada a la familia nerudiana; como un "delgado niño", sin todavía una autodefinición precisa de su quehacer artístico, "sin razón ni 
canto", aunque con la plena certeza de una individualidad que percibe el universo a partir de una embriaguez que surge del contacto con los ríos, la tierra y los árboles. En estos versos no hay mención a la casa ni al jardín de amapolas; tampoco al pozo, ni al gesto autorreflexivo del yo que lo conduce, como bien dice Loyola, "hacia el centro activo de sí mismo, hacia el descubrimiento y puesta en acción de su individualidad. Lo contrario de una fuga" (Loyola, 1974: 63) Se oculta otra vez el viaje del muchacho "que aún no es [y que] avanza hacia la revelación del destino personal" (Loyola, 2006: 64).

Neruda adulto, alejado por completo del narcisismo, subraya en esta segunda "fotografía" el cambio de encuadre y la amplitud de la visión. Por ello en el poema escribe:

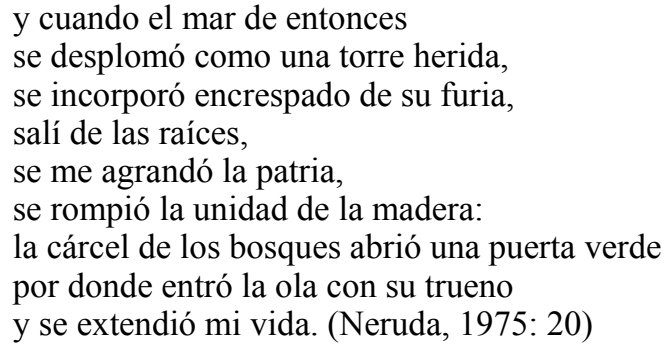

Las raíces de la madera y del bosque en este poema, desplazan y ocultan a las raíces de la tierra y a la imagen central del pozo de cuyas aguas brota el poeta en Crepusculario. Se olvida el pozo, sinécdoque del mar, porque lo que el poeta rememora es cómo "el oleaje" del mar "entraba en mi existencia" y de qué forma entraba "la ola con su trueno". El otro mecanismo utilizado en este poema para ocultar al yo del primer libro es colocar como centro de lo que se abandona no a la profundidad del pozo, sino a las raíces del bosque, de la madera. En "El primer mar" la "cárcel" que tiene enclaustrado al poeta es el bosque del niño Neftalí, no el pozo de Narciso. Es también la madera, la madre y la reemplaza por el mar, el padre océano. Con estos nuevos encuadres construidos a base de olvidos, reemplazos y desplazamientos, Neruda cierra y oculta para siempre la imagen del pozo y del poeta narcisista.

El sujeto replegado sobre sí mismo de Crepusculario está en el centro de la fotografía. Pero así como el encuadre necesita de un fondo alrededor del motivo central, el sujeto poético incorpora a su visión de mundo fragmentos de su entorno. Jaime Concha sostiene que el yo de Crepusculario entrega impresiones que "recoge de la realidad social. Prostitutas, jugadores, ciegos - como efigies predominantes de la vida colectiva-; el arrabal, la fábrica y, en general, todo el paisaje urbano manifiesta las condiciones miserables de la existencia social". Dentro de estas realidades se encuentran las máquinas sufrientes del poema "Maestranzas de noche" que revelan el lado oscuro de la modernidad y se sitúan en las antípodas del entusiasmo manifestado por Marín. El yo ingresa en los talleres, lo visto le provoca profundo malestar y cierra el poema con expresión de dolor por "las almas de los obreros muertos". 
La determinación del sujeto gramatical en este verso es indicativa de la actitud del yo. Él se manifiesta en Crepusculario como "alma" que se constituye en "un recinto privilegiado que se adorna con atributos prestigiosos" (Concha). Al mismo tiempo, el yo advierte el alma en los otros que, en este caso, es la de sujetos excluidos del progreso y de la modernidad, lo que evidencia su interés por capturar retazos del exterior en continuo cambio, atender al incesante flujo de situaciones siempre nuevas, transitorias y fugaces, y vivir atento a lo que existe fuera de él. El creador se instala así en medio de lo fugitivo y de lo infinito, se convierte en un "caleidoscopio dotado de conciencia" que recoge la multiplicidad de la vida.

El yo construye entonces una mirada doble, hacia adentro y hacia afuera, la cual se encuentra presidida por una perspectiva ideal y otra material ante la realidad. Además, se establece una relación biunívoca entre el yo y el mundo, un vínculo recíproco pues si el yo percibe a la máquina, esta tiene "una pupila abierta / para mirarme a mí". El asunto es que el yo personifica y hace suya a la máquina, pero esa percepción mediada por el adolescente se transforma en un sentimiento de angustia y compasión. Crepusculario es un miramundo que mira a dos mundos, pero a uno más que a otro. Por ello Jitrik subraya su "confesionalismo autocompasivo" en "detrimento de lo paisajístico o descriptivo" y Concha la "emotividad" a la "zaga de la marcha histórico-social"; su "dispersa motivación" anclada en una dirección sociológica, biográfica y autocognoscitiva.

\section{Palabras finales}

Alsino sueña con escapar a su precaria condición y transformar la realidad que lo circunda, pero fracasa y su anhelo de modernidad queda trunco debido a las condiciones coloniales y a la ausencia de una base material. A falta de una modernidad a nivel de lo real, como señala Raúl Bueno, Marín soluciona las insatisfacciones y carencias con la modernidad simbólica, pero la novedad del sueño de este poeta se encuentra en el tema y no en los dispositivos estéticos de la vanguardia. Si Cruchaga aterriza al avión y lo convierte en sombra inmóvil pues ve las zonas oscuras y las disonancias que amenazan al hombre, Agrella ennoblece las necesidades técnicas haciendo de ellas finalidades artísticas que se enraízan en una modernidad periférica. Él visita las grandes ciudades, elabora los signos de la modernidad y al hacerlo, familiariza la tecnología de punta de su tiempo. Neruda utiliza la máquina para retratar(se) y para advertir que también excluye y quita la vida a los más desposeídos.

La gran rueda, "árbol que sobrepasara la ciudad", se sitúa en un sitio equidistante de la Torre Eiffel y del árbol huidobriano que es más alto que la montaña como advertimos en su poema "Paisaje" de Horizon carré. Modernidad a nivel de lo real y modernidad como paisaje deseado. Si nuestra cordillera no deja pasar las ideas como señala Emar, la gran rueda nos eleva y aunque de modo fugaz y transitorio, nos permite ver destellos, apropiar el discurso del centro, recodificarlo e incluirlo en un nuevo contexto histórico y cultural donde hace sentido. De esta forma se legitima a América Latina como un lugar de enunciación diferencial, como una periferia que asumiendo "las estructuras y los dispositivos de la desigual distribución del capital, el 
conocimiento y las tecnologías" (Brunner: 177), dialoga con la modernidad central y habita la cultura del otro en cuanto relee y transforma. Así construye una modernidad que sin renegar de lo propio incluye el discurso ajeno. Así, la máquina encuentra su lugar.

\section{BIBLIOGRAFÍA}

BARBERO, Jesús Martín.

1987 De los medios a las mediaciones. Comunicación, cultura y hegemonía. México: Gili.

BARTHES, Ronald.

2008 La cámara lúcida. Nota sobre la fotografía. Buenos Aires: Paidós, $4^{\mathrm{a}}$ reimp.

BRUNNER, José Joaquín.

2002 "Modernidad", en Términos críticos de sociología de la cultura. Buenos Aires: Paidós, pp. 173-180.

CONCHA, Jaime.

EMAR, Jean.

"Proyección de Crepusculario" www.neruda.uchile.cl

1935 Miltín 1934. Santiago: Zig-Zag.

1996 Umbral. Santiago: Dibam (Centro de Investigaciones Diego Barros Arana).

2003 Notas de Arte. (Jean Emar en La Nación 1923-1927). Estudio y recopilación de Patricio Lizama. Santiago: Dibam/Ril Editores.

Del Valle, Rosamel.

1970 Eva y la fuga. Caracas: Monte Ávila editores.

GIUCCI, Guillermo.

2006 "Internacionalismo y nacionalismo: el aeroplano", Mester XXXV (2006):111-127.

JITRIK, Noé.

2003 "Neruda en el despertar de su poesía", en Crepusculario. El hondero entusiasta. Tentativa del hombre infinito. Buenos Aires: De Bolsillo, pp. 7-11.

LOYOLA, Hernán.

1974 "Pablo Neruda: ser y morir", AIH Actas V, pp. 59-78.

2006 Neruda: La biografia literaria. Santiago: Seix Barral.

NERUDA, Pablo

1975 Memorial de Isla Negra. Buenos Aires: Losada, $3^{\text {a }}$ edc.

2003 Crepusculario. El hondero entusiasta. Tentativa del hombre infinito.

Pról. de Noé Jitrik. Buenos Aires: De Bolsillo.

2005 Confieso que he vivido. Santiago: Planeta Chilena, $2^{\mathrm{a}}$ edc. 
SILVA, Sergio.

1981 "Alcances y riesgos de la técnica moderna", Revista Universitaria 6 (1981):79-91.

1985 "La técnica moderna en la crisis cultural de nuestro tiempo", Revista Universitaria 14 (1985):18-25.

SUBERCASEAUX, Bernardo.

1999 Genealogía de la vanguardia en Chile, La década del centenario. Santiago: Universidad de Chile, 1999.

WILLIAMS, Rosalynd.

1997 "Mundos de ensueño del consumo", en David Crowley y Paul Heyer (eds.). La comunicación en la historia. Tecnología, cultura, sociedad. Barcelona: Bosch Casa Editorial, 1997, pp. 235-243. 